\title{
Penataan Lingkungan Demfarm Kakao Berbasis Masyarakat dan Agrowisata Berkelanjutan di Kabupaten Soppeng Sulawesi Selatan
}

\author{
Arrangement of Cocoa Community-Based Demfarm Site and \\ Sustainable Agro-Tourism in Soppeng Regency, South Sulawesi
}

\author{
ANTON GUNARTO \\ Pusat Teknologi Produksi Pertanian, Badan Pengkajian dan Penerapan Teknologi \\ Laptiab Gd. 612 Puspiptek Serpong Tangerang Selatan 15314 \\ anton.gupra@gmail.com
}

\begin{abstract}
South Sulawesi have faced low cocoa productivity problem that is still far away from its potential. One of the effort to increase the productivity could be achieved through a demonstration farming (demfarm) establishment. This method is useful to disseminate the standard cocoa process culture to cocoa farmers through pilot project and training. The research objective is to develop a cocoa demfarm landscape planning and concept in Soppeng Regency, South Sulawesi. The landscape consisted of culture technology dissemination, nursery and processing facility and also cocoa community-based agro-tourism development. The planning combined the environmental-friendly concept of cocoa demfarm arrangement and landscape based on the aesthetic (beauty) principles and functional (usefulness) of a region. The landscape design manifested in a site planned dominated by geometric patterns which consisted of soft element site such as cocoa tree and thematic ornamental plant. The zonation are public area (4\%), recreation area (9\%), production area (81\%), and private area (6\%).
\end{abstract}

Keywords: Cocoa, Demfarm, Agro-tourism

\begin{abstract}
ABSTRAK
Permasalahan kakao di Sulawesi Selatan yaitu produktivitasnya rendah, masih jauh dari potensi produktivitas yang bisa dicapai. Salah satu upaya meningkatkan produktivitas kakao melalui demfarm (demonstration farming) untuk diseminasi (penyebaran) teknologi budidaya standar dan pengolahan kakao standar melalui percontohan dan pelatihan kepada petani kakao. Tujuan penelitian adalah menyusun suatu konsep dan perencanaan penataan lansekap demfarm kakao sebagai sarana diseminasi inovasi teknologi budidaya, pembibitan dan pengolahan kakao, sekaligus pengembangan menuju konsep agrowisata kakao berbasis masyarakat di Kabupaten Soppeng. Konsep penataan memadukan antara konsep penataan demfarm kakao dan pertamanan yang diupayakan berpedoman pada kaidah-kaidah estetika (keindahan) dan fungsional (kegunaan) suatu kawasan serta kaidah-kaidah pembangunan berkelanjutan. Desain lanskap diwujudkan dalam bentuk site plan yang didominasi pola geometris yang terbentuk dari elemen lunak tapak seperti tanaman kakao dan tanaman hias taman tematiknya. Zonasi yang dibuat, yaitu : Zona umum (4\%), Zona rekreasi $(9 \%)$, Zona produksi $(81 \%)$, dan Zona pribadi (6\%).
\end{abstract}

Kata Kunci: Kakao, Demfarm, Agrowisata.

\section{PENDAHULUAN}

\subsection{Latar Belakang}

Secara nasional tanaman kakao (Theobroma cacao L.) adalah salah satu tanaman perkebunan yang memiliki nilai ekonomis baik, karena komoditas kakao menghasilkan devisa terbesar ketiga setelah kelapa sawit dan karet. Secara internasional, Indonesia merupakan produsen kakao terbesar ketiga setelah Pantai Gading dan Ghana $^{(1)}$ dengan produksi pada tahun 2014 mencapai 728.414 ton dan luas areal mencapai 1.727.437 ha yang tersebar di seluruh propinsi, kecuali DKI Jakarta ${ }^{(2)}$. Perkembangan luas area kakao di Indonesia menurun namun produksinya meningkat. Pada tahun 2013, area kakao mencapai 1.740 .612 ha dengan produksi 720.862 ton dan pada tahun 2014 area kakao menurun menjadi 1.727.437 ha tetapi produksinya naik menjadi 728.414 ton. Dari tahun 2011 s.d. 2015 ternyata produktivitas kakao mengalami laju penurunan 2,21 \% per tahun dengan rata-rata produktivitas $818 \mathrm{~kg} / \mathrm{ha}$. Sekitar 97,61 \% komoditas kakao adalah perkebunan kakao rakyat dan selebihnya berupa 
perkebunan negara $(0,88 \%)$ dan swasta $(1,51$ $\%)$.

Sentra produksi kakao di Indonesia berada di wilayah Sulawesi, di mana pada tahun 2014 menyumbang $67 \%$ produksi kakao nasional. Produksi kakao di Sulawesi antara tahun 2013 dan 2014 cenderung meningkat yaitu dari 467.070 ton naik menjadi 484.387 ton, kecuali luas areal menurun dari 998.138 ha menjadi 996.241 ha dan produktivitas dari $876 \mathrm{~kg} / \mathrm{ha}$ turun menjadi $855 \mathrm{~kg} / \mathrm{ha}^{(2)}$, masih jauh dari potensi produktivitas yang bisa dicapai yaitu $1.000-1.500 \mathrm{~kg} / \mathrm{ha}$.

Dari aspek produktivitas kakao di wilayah Sulawesi tahun 2014, Sulawesi Utara dan Sulawesi Selatan memiliki produktivitas terendah yaitu masing-masing $673 \mathrm{~kg} / \mathrm{ha}$ dan $802 \mathrm{~kg} / \mathrm{ha}$, sedangkan yang tertinggi adalah Sulawesi Tengah yaitu $908 \mathrm{~kg} / \mathrm{ha}$.

Dalam penataan perekonomian wilayah Sulawesi Selatan banyak bertumpu pada komoditas kakao. Komoditas kakao telah dijadikan sebagai "komoditas citra unggulan" di wilayah ini. Luas areal kakao di Sulawesi Selatan tahun 2014 mencapai 250.175 ha dengan total produksi sebesar 118.329 ton biji kering/tahun ${ }^{(2)}$. Kakao dibudidayakan petani dan tersebar di berbagai kabupaten di wilayah Provinsi Sulawesi Selatan, salah satunya adalah Kabupaten Soppeng.

Beberapa masalah penurunan produktivitas yang dihadapi petani kakao adalah kondisi tanaman yang sudah tua, terkena serangan organisme pengganggu tanaman, rendahnya teknik budidaya pemeliharaan tanaman kakao, serta keterbatasan infrastruktur pendukung bagi kegiatan perkebunan seperti pengelolaan sumber daya tanah yang kurang tepat dan industri pengolahan kakao, seperti rendahnya kualitas produk biji kakao karena teknik pengolahan yang kurang memadai sehingga pasar kurang bisa menerima produk-produk biji bermutu.

Dalam program Masterplan Percepatan dan Perluasan Pembangunan Ekonomi Indonesia (MP3EI), untuk mendukung peningkatan mutu dan hilirisasi produksi kakao, diperlukan dukungan terkait regulasi dan kebijakan, salah satunya ialah dengan melakukan Gerakan Nasional (GERNAS) Biji Kakao Fermentasi sebagai komitmen dan persetujuan aksi bersama peningkatan dan perbaikan produksi, produktivitas, dan mutu kakao Indonesia. Tujuan program tersebut adalah untuk mendukung program peningkatan mutu dan hilirisasi produksi kakao serta meningkatkan kualitas dan kuantitas produksi kakao nasional melalui penyediaan bibit unggul; penerapan teknik budidaya standar, dan pengolahan kakao standar. Salah satu sasaran dari program tersebut adalah mendapatkan demfarm (demonstration farming) untuk diseminasi (penyebaran) teknologi budidaya dan pengolahan kakao melalui percontohan dan pelatihan kepada petani kakao.

Pembangunan demfarm perkebunan kakao didesain mengikuti kaidah-kaidah pembangunan pertanian berkelanjutan dan berwawasan lingkungan. Hal tersebut selaras dengan pernyataan dari Direktur Tanaman Tahunan dan Penyegar, Direktorat Jenderal Perkebunan, Kementerian Pertanian Sudjatmiko dalam majalah Coklat Edisi 12 Januari-Mei 2016 bahwa inti dari Program Pengembangan Kakao Berkelanjutan adalah tidak sekadar melakukan pengembangan di sektor produksi (hulu), tapi juga hingga pada sektor pengolahan (hilir), yang semuanya mengarah pada upaya peningkatan pendapatan petani. Juga yang dititikberatkan pada penguatan kelembagaan petani dan pembenahan pasar. Dan semua itu adalah rangkaian dalam menuju kakao keberlanjutan Indonesia, dengan alasan bahwa jika penjangkauan hanya pada sektor hulu saja, tidak menjangkau hingga hilir, maka tidak bisa dikatakan sebagai hal yang berkelanjutan, karena hanya menyentuh sebagian saja.

Pembangunan berwawasan lingkungan diartikan bahwa pembangunan dilakukan tidak perlu merusak lingkungan. Pembangunan sebagai proses perubahan dan pembaharuan yang merupakan suatu upaya yang secara sadar ingin mencapai perbaikan kehidupan dan kualitas hidup seharusnyalah merupakan suatu proses yang selalu dapat ditopang oleh lingkungan yang ikut berkembang daya dukung/daya topangnya ${ }^{(3)}$. Jika dikaitkan dengan pertanian, maka istilah berkelanjutan menggambarkan tentang system pertanian yang mampu mempertahankan produktivitasnya dan memiliki sisi manfaat bagi masyarakat sekitar. Sistem pertanian tersebut haruslah memiliki faktor dan unsur konservasi sumberdaya, sosial, komersial, kompetitif, dan bersahabat dengan lingkungan ${ }^{(4)}$.

\subsection{Tujuan Penelitian}

Tujuan penelitian adalah menyusun suatu konsep dan perencanaan penataan lanskap demfarm kakao sebagai sarana diseminasi inovasi teknologi budidaya, pembibitan dan pengolahan kakao, sekaligus pengembangan menuju konsep agrowisata kakao berbasis masyarakat yang berwawasan lingkungan di Kabupaten Soppeng.

Konsep penataan tersebut mencoba memadukan antara konsep penataan demfarm kakao dan pertamanan yang diupayakan berpedoman pada kaidah-kaidah estetika (keindahan) dan fungsional (kegunaan) suatu kawasan serta kaidah-kaidah pembangunan berkelanjutan. 
Sasaran yang ingin dicapai adalah tersusunnya konsep pengembangan demfarm sebagai sarana kegiatan diseminasi inovasi teknologi budidaya, pembibitan dan pengolahan kakao yang sekaligus di desain pula menjadi sarana kegiatan agrowisata kakao yang berwawasan lingkungan, sehingga demfarm akan bermanfaat ganda bagi masyarakat.

\section{BAHAN DAN METODE}

\subsection{Metode}

Metodologi yang digunakan berdasarkan pendekatan metode framework perencanaan ${ }^{(5)}$ yang terdiri dari persiapan, inventarisasi, analisis, sintesis hingga konsep perencanaan taman, antara lain berupa konsep perencanaan lanskap yang sesuai dengan fungsi dalam tapak (zonasi, penataan, sirkulasi, fasilitas), aktifitas dan kemauan pengelola/ pemilik/ pengguna/ masyarakat.

\subsection{Pengumpulan Data}

Jenis data yang diperlukan yaitu data primer dan data sekunder. Data primer adalah data yang diperoleh melalui wawancara, survei lokasi dan observasi. Sedangkan data sekunder adalah data yang diperoleh dari laporan, literatur, publikasi dan dokumen lainnya dari lembaga/instansi terkait. Beberapa informasi data terdiri dari aspek biofisik, aspek teknik dan aspek sosial ekonomi.

\subsection{Lokasi dan Waktu}

Lokasi penelitian di Jalan Kampung Baru Kota Takalala, Kelurahan Tettikenrarae, Kecamatan Marioriwawo, Kabupaten Soppeng Propinsi Sulawesi Selatan. Status kepemilikan lahan Takalala adalah milik petani yaitu Bapak Hasnul.

Beberapa pertimbangan memilih lahan demfarm adalah : (a) Luas kebun lebih dari 2 ha, (b) Tanaman tumbuh baik (sambung samping), (c) Tanaman berumur 10 tahun dan produktif, (d) Dekat kampung, (e) Banyak kebun kakao disekitarnya, (f) Ada aliran listrik, (g) Sumber air adalah bor, (h) Tersedia lahan kosong untuk pembibitan serta kebun kakao lain untuk penelitian dan kegiatan seleksi, (i) Berada dipinggir jalan raya, (j) Jarak dari kota relatif dekat, (k) Kebun kakao berada di pertengahan kebun kakao milik petani lain, (I) Topografi relatif landai, (m) Pemilknya mau bekerjasama.

Waktu pelaksanaan penelitian yaitu mulai Januari s.d. Oktober 2016.

\section{HASIL DAN PEMBAHASAN}

\subsection{Kondisi Awal Demfarm}

Vegetasi yang paling dominan pada kebun demfarm tersebut adalah tanaman kakao dengan populasi 1163 pohon berjarak tanam $4 \times 4 \mathrm{~m}$. Vegetasi lainnya adalah pohon kelapa, jati, nipah, jeunjing, bambu, pisang, alang-alang dan tanaman liar lainnya. Topografi kebun relatif landai dekat dengan perkampungan penduduk sehingga berpeluang besar untuk melakukan diseminasi teknologi budidaya dan pengolahan kakao.

Batas-batas lokasi demfarm di sebelah utara adalah jalan Kampung Baru yang beraspal hotmix dan kebun kakao rakyat, di sebelah selatan adalah kebun kakao rakyat, disebelah timur adalah kebun campuran, dan di sebelah barat adalah kebun kakao rakyat. $\mathrm{Di}$ area kebun campuran terdapat satu buah rumah penduduk, sementara di pinggir jalan Kampung Baru yang bersebelahan dengan lokasi demfarm di sebelah kiri dan kanannya terdapat beberapa rumah penduduk lainnya.

Jarak dari demfarm ke jalan raya poros Maros-Soppeng dan Kantor Kecamatan Mariorirawo atau ibukota kecamatan Takalala 1-2 $\mathrm{km}$. Jarak dari demfarm di Kelurahan Tettikenrarae Takalala ke ibukota Kabupaten Soppeng yaitu Watan Soppeng $17 \mathrm{~km}$ dan ke ibukota propinsi Sulawesi Selatan yaitu Makasar $150 \mathrm{~km}$. Sementara jarak ke kota-kota terdekat seperti Singkang $45 \mathrm{~km}$, Pare-pare $96 \mathrm{~km}$ dan Maros $108 \mathrm{~km}$.

\subsection{Tentang Kecamatan Marioriwawo}

Data dari BPS Kabupaten Soppeng ${ }^{(6)}$ bahwa Marioriwawo adalah sebuah kecamatan di Kabupaten Soppeng, Propinsi Sulawesi Selatan. lbukota kecamatan ini yaitu Takalala. Jarak tempuh antara kecamatan ini ke kota Makassar kurang lebih $175 \mathrm{~km}$ via Buludua. Memang untuk memasuki wilayah ini dari kota Makassar terdapat beberapa jalur yang dapat dilewati yakni via Buludua (terdekat), via Camba, dan via Parepare (terjauh).

Keadaan Geografis Kecamatan Marioriwawo dengan luas $300 \mathrm{~km}^{2}$, berada di bagian selatan Kabupaten Soppeng. Pemerintah Kecamatan Marioriwawo terdiri atas 2 kelurahan dan 11 desa. Kecamatan ini berada pada wilayah dengan topografi yang beragam. Sebagian desa berada pada wilayah yang datar dan lainnya berada pada wilayah dengan topografi berbukitbukit. Secara keseluruhan wilayah Kecamatan Marioriwawo berada pada ketinggian antara 25$1.400 \mathrm{~m}$ dpl. Sebagian besar wilayah dari kecamatan ini adalah daerah pegunungan, jadi tidak salah kalau daerah ini terkenal dengan 
suhu dingin dan pemandangan alam yang sangat menyejukkan mata.

Berdasarkan Sensus Penduduk 2010, penduduk Kecamatan Marioriwawo sebanyak 44.310 jiwa, dengan penduduk laki-laki 20.701 jiwa dan perempuan 23.609 jiwa. Kelurahan Tettikenrarae merupakan kelurahan dengan kepadatan terbesar yaitu 401 jiwa $/ \mathrm{km}^{2}$. Sedangkan yang terendah adalah Desa Soga dengan kepadatan penduduk $70 \mathrm{jiwa} / \mathrm{km}^{2}$.

Sebagian besar mata pencaharian penduduk adalah bertani, baik petani kebun maupun petani persawahan. Hasil pertanian yang paling banyak dihasilkan yaitu kakao dan beras. Selain itu tidak sedikit pula penduduk dari kecamatan ini adalah pedagang dan pegawai.

Wilayah ini sangat potensial di jadikan sebagai tujuan wisata, terdapat banyak tempat yang betul-betul masih alami, ditambah pemandangan persawahan yang tidak kalah dengan Ubud Bali. Bila memasuki wilayah kecamatan ini via Bulu Dua, pesona alam yang indah ini akan menyambut perjalanan yang menyenangkan.

Luas Kecamatan Marioriwawo yaitu 30.000 ha, terdiri dari lahan sawah seluas 2.998 ha, lahan bukan sawah dan bukan pertanian seluas 27.002 ha. Lahan tersebut digunakan untuk menanam berbagai jenis seperti pangan, buah, sayuran dan tanaman perkebunan seperti kakao, kelapa dalam, kemiri, jambu mete dan kapas.

Kecamatan Marioriwawo merupakan wilayah di Kabupaten Soppeng dengan potensi pertanian padi yang cukup besar. Pada tahun 2010, menghasilkan produksi padi sebanyak 29.914 ton, yang dihasilkan dari areal tanam seluas 6.634 ha. Hasil perkebunan yang cukup menonjol adalah kakao dan kelapa dalam (hybrida). Pada Tahun 2013-2014 menghasilkan produksi kakao rata-rata 5.180 ton dari luas areal tanam rata-rata 7.021 ha, sedangkan untuk kelapa dalam (hibrida) menghasilkan produksi rata-rata 591 ton dari luas areal tanam rata-rata 554 ha. Pada Tahun 2010, kecamatan ini memiliki ternak sapi 4.644 ekor, ayam buras sebanyak 256.168 ekor, dan itik sebanyak 6.552 ekor.

Sarana komunikasi di Kecamatan Marioriwawo cukup memadai dengan ketersediaan jaringan telepon baik jenis telepon kabel maupun yang nirkabel (selular). Pada tahun 2010, terdapat 266 pelenggan telepon kabel di wilayah Tettikenrarae dan Labessi. Untuk transportasi, semua desa dan kelurahan di Kecamatan Marioriwawo sudah terjangkau oleh kendaraan.

\subsection{Konsep Dasar Demfarm Kakao}

Pengertian Demfarm (Demontration Farming) atau demonstrasi usaha tani berkelompok merupakan demonstrasi yang dilakukan secara kerjasama oleh petani dalam suatu kelompok $\operatorname{tani}^{(7)}$. Luas lahan yang digunakan 1-5 ha. Tujuan pelaksanaan demfarm untuk meningkatkan pengetahuan dan keterampilan anggota kelompok tani serta memberi contoh petani disekitarnya menerapkan teknologi baru melalui kerjasama kelompok ${ }^{(8)}$.

Demfarm di Kabupaten Soppeng atau demfarm Takalala adalah suatu metode desiminasi (penyebaran) di lapangan untuk memperlihatkan secara nyata cara atau hasil penerapan suatu inovasi teknologi pertanian dan pasca panen tanaman kakao yang telah teruji dan menguntungkan bagi petani yang dilaksanakan oleh petani/kelompok tani dengan skala luas sekitar 2 ha di mana komoditas utama adalah kakao dan produk-produk olahannya.

\subsection{Demfarm Berbasis Masyarakat}

Konsep dasar pengembangan demfarm yang dihadirkan adalah konsep agrowisata yang menyertakan masyarakat petani kakao setempat melalui kelompok tani atau organisasi masyarakat lainnya. Menghadirkan konsep agrowisata kakao berbasis masyarakat diharapkan dalam pengembangan kawasan dapat mengikutsertakan masyarakat atau petani pemilik lahan di sekitar tapak, sehingga lahan demfarm bisa menjadi lebih luas seiring dengan kebutuhan penyediaan fasilitas-fasilitas yang diperlukannya.

Sarana utama yang dirancang adalah sarana untuk kegiatan diseminasi inovasi teknologi kakao (budidaya, pembibitan, pengolahan) dan penelitian/percobaan serta rekreasi (wisata) pertanian kakao. Ditinjau dari aspek fungsi maka kawasan demfarm Takalala berperan sebagai kebun inti, sementara kebun-kebun kakao disekitarnya diharapkan berkembang menjadi kebun-kebun plasmanya.

\subsection{Agrowisata Kakao Berkelanjutan}

$\begin{array}{ccc}\text { Agrowisata atau wisata pertanian } & \text { ata } \\ \text { didefinisikan sebagai } & \text { rangkaian aktivitas }\end{array}$ perjalanan wisata yang memanfaatkan lokasi atau sektor pertanian mulai dari awal produksi hingga diperoleh produk pertanian dalam berbagai sistem dan skala dengan tujuan memperluas pengetahuan, pemahaman, pengalaman dan rekreasi di bidang pertanian ${ }^{(9)}$. Adanya pengembangan agrowisata berbasis masyarakat di perdesaan diharapkan dapat memberi manfaat yang banyak, tidak saja bagi masyarakat perdesaan tetapi juga masyarakat perkotaan untuk lebih memahami dan memberikan apresiasi pada bidang pertanian serta menjadi sarana edukasi.

Manfaat pengembangan agrowisata berbasis masyarakat perdesaan ${ }^{(10)}$, yaitu : (1) secara langsung dan tidak langsung akan meningkatkan 
persepsi positif petani serta masyarakat akan arti pentingnya pelestarian sumber daya lahan pertanian, pelestarian kearifan dan teknologi lokal, dan (2) akan menciptakan lapangan pekerjaan dan meningkatkan pendapatan petani di luar nilai kuantitas produksinya atau pendapatan masyarakat sekitar agrowisata.

Pengembangan kawasan pertanian menjadi area agrowisata akan meningkatkan kunjungan wisatawan yang akan memberikan kontribusi peningkatan pendapatan masyarakat melalui jasa wisata ${ }^{(11)}$. Pengembangan desa wisata pertanian berdampak positif bagi sektor pertanian dan masyarakatnya, sejalan dengan hal tersebut, diperlukan peningkatan SDM perdesaan agar peran serta masyarakat lebih besar dalam pengelolaan $^{(12,13)}$.

Konsep keberlanjutan menjadi faktor penting dalam pengelolaan sektor pertanian, mengingat alih fungsi lahan terus terjadi dan mengancam keberlanjutan sistem pertanian. Ecovillage adalah satu konsep keberlanjutan yang sedang berkembang saat ini, merupakan konsep ideal antara segi ekologis, sosial, dan spiritual dalam hubungan antara manusia dan lingkungan untuk keberlanjutan kehidupan generasi berikutnya ${ }^{(14)}$.

\subsection{Konsep Desain}

Konsep desain pada perancangan demfarm Takalala ini adalah geometris alami. Pola geometris memberikan keuntungan berupa mudahnya pengaturan drainase, pengelolaan limbah, serta pemanfaatan sinar matahari. Konsep geometris alami merupakan kombinasi antara bentukan-bentukan geometris yang didukung oleh peran penataan elemen-elemen halus tapak.

\subsection{Konsep Pengembangan}

Dalam pengembangan demfarm Takalala menuju konsep agrowisata kakao berbasis masyarakat, tidak bisa bergantung pada lahan milik Bapak Hasnul saja tetapi memerlukan partisipasi petani lainnya yang memiliki lahan yang bersebelahan dengan lahan milik bapak Hasnul. Berdasarkan dari Peta dasar dan peta citra satelit dapat terlihat bahwa lahan milik petani lain yang cocok untuk dijadikan perluasan lahan kawasan demfarm adalah pada kebunkebun campuran yang berada di sebelah timur lahan dan kebun milik Bapak Hasnul. Diasumsikan bahwa petani-petani tetangga tersebut ikut berpartisipasi dalam pengembangan dan perluasan kawasan demfarm Takalala.

Konsep ruang Demfarm Takalala dibagi kedalam beberapa zona ${ }^{(15)}$ dan masing-masing zona memiliki sub-zona yang fungsi ruangnya lebih spesifik. Zona yang dibuat dalam perancangan ini (Lihat Gambar 1 dan Gambar 2), adalah :

(1) Zona umum, yang terdiri dari: (a) sub-zona penerima (edukasi dan interpretasi) dan (b) sub-zona parkir.

(2) Zona, rekreasi, terdiri dari: (a) sub-zona produk coklat dan (b) sub-zona wisata.

(3) Zona produksi, terdiri dari: (a) sub-zona kebun wisata, (b) sub-zona kebun penyangga, (c) sub-zona kebun budidaya, (d) sub-zona kebun pembibitan, (e) sub-zona kebun penelitian, dan (f) sub-zona pascapanen.

(4) Zona pribadi, terdiri dari: (a) sub-zona rumah pondok, dan (b) sub-zona gedung utilitas (instalasi air, instalasi listrik, gudang).

Pada Gambar 2 terlihat bahwa lahan milik Bapak Hasnul adalah lahan nomor 3.a sebagai sub-zona kebun wisata, 3.b sebagai sub-zona kebun penyangga, 3.c sebagai sub-zona kebun budidaya, 3.d sebagai sub-zona kebun pembibitan dan 3.e sebagai sub-zona kebun penelitian. Sedangkan sisanya adalah lahan di luar milik Bapak Hasnul sebagai perluasan lahan milik petani lainnya yang ikut berpartisipasi dalam program ini.

Rencana jalur wisata akan memudahkan wisatawan dalam menginterpretasi berbagai obyek dan daya tarik wisata yang disesuaikan dengan tujuan wisata. Penyusunan rencana jalur wisata disesuaikan dengan konsep sirkulasi serta terintegrasi secara utuh dengan paket wisata yang ditawarkan. Untuk jelasnya jalur agrowisata dari demfarm Takalala ke ibu kecamatan Marioriwawo dan ke kota-kota besar lainnya melalui jalan kabupaten (Jalan Kampung Baru) dan jalan propinsi (Jalan poros Maros-Soppeng) dapat dilihat pada Gambar 3. Pengunjung yang akan datang ke Demfarm Takalala diharapkan bisa mendapatkan informasi tentang dunia pertanian melalui kegiatan wisata terpadu, khususnya kakao dan produknya.

\subsection{Perancangan Lanskap}

Penambahan fungsi demfarm Takalala sebagai sarana agrowisata mengharuskan adanya tambahan fasilitas untuk berwisata di tapak. Fasilitas wisata yang disebutkan ${ }^{(16)}$, adalah: gerbang masuk, fasilitas informasi, area parkir, toilet, area piknik, taman bermain anak, jalur berwisata, rekreasi air, wildlife viewing, fasilitas wisata malam, dan interpretasi. Penerapan fasilitas wisata di demfarm Takalala tidak semua diterapkan namun disesuaikan dengan visi/misi pengelola, ketersediaan dana dan kebutuhan pengunjung/pasar.

Pengembangan dan perluasan tapak demfarm Takalala dengan luas $\pm 32.470 \mathrm{~m}^{2}$ atau 
3,247 ha yang dirancang terdiri dari empat zona, yaitu :

a) Zona Umum: Luas $=42 \times 30 \mathrm{~m}=1.260 \mathrm{~m}^{2}(4 \%)$

b) Zona Rekreasi: Luas $=58 \times 50 \mathrm{~m}=2.900 \mathrm{~m}^{2}(9$ $\%)$ c) Zona Produksi: Luas $=50 \times 42 \mathrm{~m}=2.100 \mathrm{~m}^{2}+$ $24.210 \mathrm{~m}^{2}=26.310 \mathrm{~m}^{2}(81 \%)$

d) Zona Pribadi: Luas $=50 \times 40 \mathrm{~m}=2.000 \mathrm{~m}^{2}(6$ $\%)$.

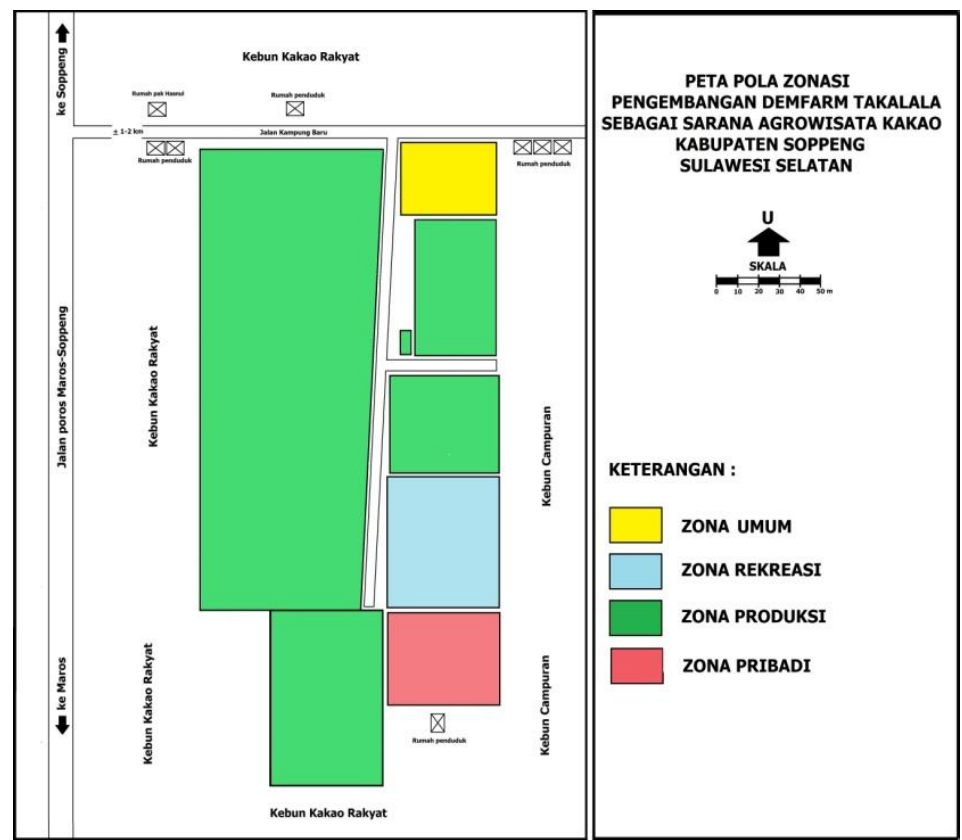

Gambar 1. Peta pola zonasi pengembangan demfarm Takalala ${ }^{(15)}$

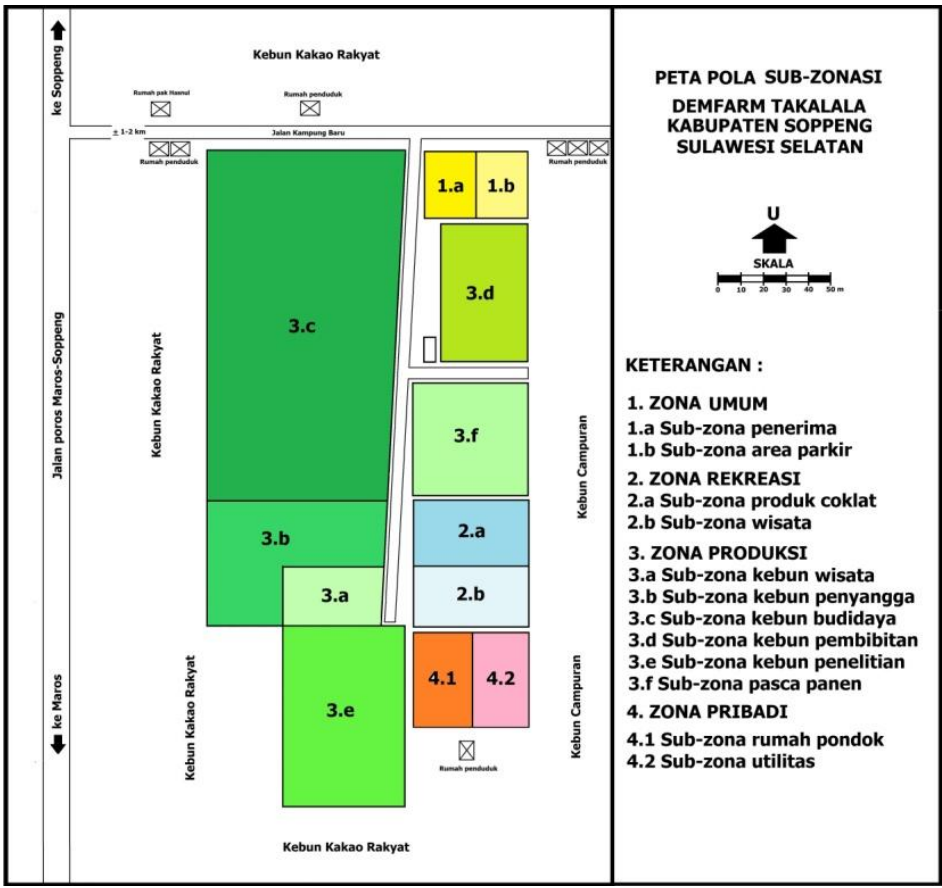

Gambar 2. Peta pola sub-zonasi pengembangan demfarm Takalala 


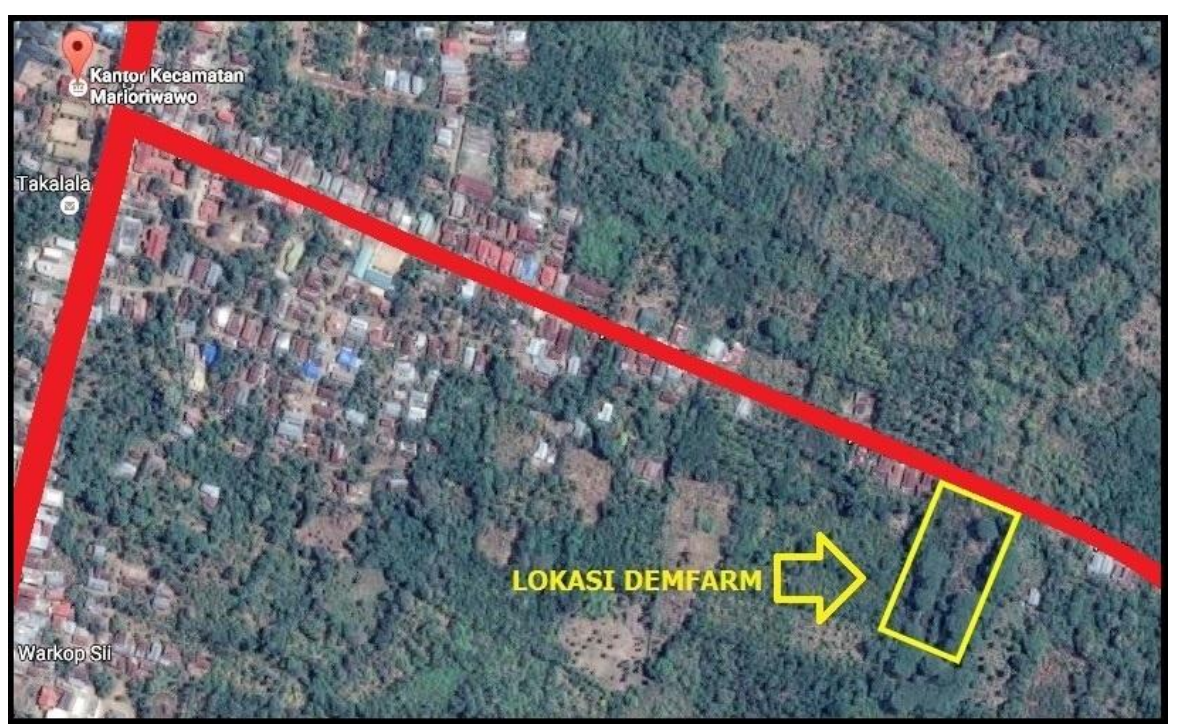

Gambar 3. Peta citra satelit jalur wisata agro demfarm Takalala

Adapun tambahan fasilitas sarana dan prasarana demfarm Takalala sebagai kebun agrowisata, antara lain :

(1) Gapura

(2) Plaza edukasi dan interpretasi (foto selfie), seluas $=30 \times 21 \mathrm{~m}=630 \mathrm{~m}^{2}$

(3) Area parkir kendaraan, seluas $=30 \times 21 \mathrm{~m}=$ $630 \mathrm{~m}^{2}$

(4) Gedung pengolahan produk coklat, seluas = $26 \times 8 \mathrm{~m}=208 \mathrm{~m}^{2}$

(5) Kios cinderamata produk coklat, seluas $=6 x$ $6 \mathrm{~m}=36 \mathrm{~m}^{2}$

(6) Toilet umum, seluas $6 \times 4 \mathrm{~m}=42 \mathrm{~m}^{2}$

(7) Kafetaria, seluas $15 \times 10 \mathrm{~m}=150 \mathrm{~m}^{2}$

(8) Musholla, seluas $15 \times 10 \mathrm{~m}=150 \mathrm{~m}^{2}$

(9) Taman bermain anak, seluas $=20 \times 10 \mathrm{~m}=$ $200 \mathrm{~m}^{2}$

(10) Taman tematik untuk rekreasi/wisata lainnya, seluas $=50 \times 30 \mathrm{~m}=1.500 \mathrm{~m}^{2}$

(11) Gedung utilitas (instalasi air, instalasi listrik, gudang), seluas $=10 \times 5 \mathrm{~m}=50 \mathrm{~m}^{2}$

(12) Pagar di sekeliling kawasan sepanjang 790 $\mathrm{m}$.

Rancangan tapak didominasi oleh penggunaan elemen lunak berupa tanaman kakao sebagai penciri khas kawasan. Elemen lunak di tapak didominasi oleh kebun dengan komoditas kakao dan dengan mayoritas komoditas tanaman produksi. Vegetasi pada taman-taman tematik yang dipilih diharapkan bisa memecah kekakuan pola geometris tapak. Elemen keras di tapak hanya diterapkan pada elemen tertentu seperti bangunan, jalur sirkulasi, plaza, signage dan site furniture. Site plan Demfarm Takalala bisa dilihat pada Gambar 4.

Kegiatan yang ditawarkan antara lain berjalan di blok tanaman kakao sambil mendapatkan informasi mengenai buah-buah tersebut, melakukan perbanyakan tanaman, pengenalan screen house, melakukan perawatan tanaman, pemanenan buah, penanganan pasca panen dan melihat proses pengolahan produknya menjadi berbagai jenis coklat dan lainnya yang disesuaikan dengan kondisi tapak dan musim tertentu.

Pada subzona kebun rekreasi, pengunjung diperkenankan untuk ikut panen memetik buah coklat dan atau membeli dan menimbangnya, tentunya didampingi oleh pemandu kebunnya. Termasuk membeli bibit-bibit tanaman kakaonya. Pada subzona penyangga atau kebun koleksi beberapa varietas kakao, pengunjung hanya diperkenankan untuk melihat pemandangan (view/vista) perkebunan kakao dan berfoto ria. Pada subzona produk kakao merupakan area yang difasilitasi bagi pengunjung untuk melihat proses pengolahan biji kakao menjadi berbagai macam produk kakao seperti coklat bubuk, coklat batangan, permen coklat, minuman hangat coklat-susu dan lain-lain yang disediakan di kioskios makanan dan cinderamata/buah tangan serta restoran atau cafe.

Salah satu masalah lingkungan di perkebunan kakao adalah limbah kulit buah dan gugur daun kakao, sehingga kebun terlihat kotor dan tidak asri/estetik, di mana kondisi tersebut tidak layak menjadikan kebun kakao sebagai demfarm. Untuk memfasilitasi pemanfaatan limbah tersebut maka di depan area pembibitan terdapat bangunan untuk membuat pupuk organik bokashi dan kompos berbahan dasar organik seperti limbah pertanian, daun-daun kakao, kulit kakao, arang sekam, jerami, pupuk kandang (ayam) yang banyak terdapat di desa ini, EM4, gula pasir/aren dan lain-lain. Bahkan limbah kulit kakao bisa pula dimanfaatkan untuk pakan ternak. 


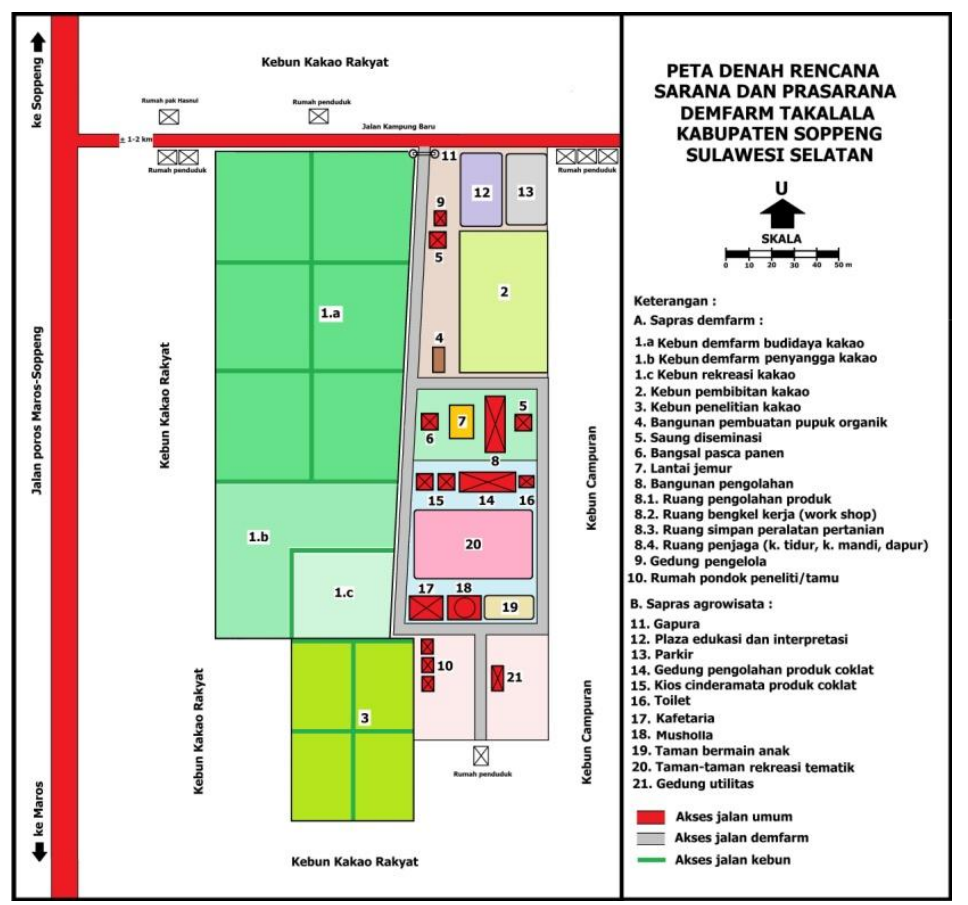

Gambar 4. Peta denah rencana (Site plan) sarana dan prasarana demfarm Takalala

Potensi limbah kakao sebagai sumber bahan organik cukup besar. Limbah dapat berupa daun guguran, kulit buah dan plasenta. Bobot kering daun gugur pada tanaman kakao meningkat menurut umur. Pada umur 10 tahun diperkirakan $5,5 \mathrm{t} /$ ha/tahun $^{(17)}$, sementara itu kulit dan plasenta bobotnya sebanding dengan biji yang dihasilkan $^{(18)}$.

Limbah kakao mengandung sejumlah unsur hara penting. Jumlah unsur hara setara pupuk pada daun gugur dan kulit buah dengan produktivitas $1.000 \mathrm{~kg}$ biji kering/ha yaitu $200 \mathrm{~kg}$ Urea, 75 kg TSP, 640 kg KCl, dan 210 kg Kiserit per ha. Jika limbah ini dimanfaatkan sebagai pupuk, petani telah ikut berperan membantu program pemerintah dalam hal penghematan penggunaan energi (pupuk buatan) dan pembangunan berwawasan lingkungan. Jika luas tanaman kakao di Sulawesi Selatan sekitar $200.000 \mathrm{ha}$, dengan hasil $1.000 \mathrm{~kg} / \mathrm{ha}$ dan pemanfaatan limbah kakao setara pupuk sekitar $1.000 \mathrm{~kg}$, sementara harga pupuk diperkirakan Rp 2.500/kg, maka jumlah penghematan atas penggunaan limbah kakao ditaksir sekitar Rp 500 Milyar/tahun, suatu jumlah yang cukup banyak. Dengan demikian pendapatan petani akan meningkat $\mathrm{Rp} 2.500 .000 /$ ha, lahan pertanaman kakao tetap terjamin kesuburannya dan produksi kakao diharapkan meningkat dan stabil ${ }^{(19)}$. Untuk dapat menjadi pupuk organik, limbah kakao harus mengalami dekomposisi (pelapukan), melalui pemanfaatan mikro organisme tanah (dekomposer). Beberapa mikro organisme lokal (MOL) teridentifikasi potensial sebagai dekomposer dan beberapa produk MOL sudah beredar dan dipasarkan di lapang di mana di antaranya dapat dikembangkan secara sederhana oleh petani ${ }^{(19)}$.

Hasil kegiatan $^{(19)}$ menunjukkan bahwa jenis MOL yang paling efektif dalam pengolahan limbah kakao menjadi pupuk organik yang diaplikasikan pada kakao produktif adalah MOL Pepaya dibandingkan MOL Keong, MOL Nasi dan MOL Bayam. Sedangkan penggunaan dosis pupuk organik limbah kakao (POLK) sebesar $2 \mathrm{t}$ POLK/ha + 300 NPK kg/ha merupakan kombinasi pupuk yang dapat meningkatkan 41-54\% produktivitas kakao, dibandingkan POLK 2 t/ha + $900 \mathrm{~kg} \mathrm{NPK} / \mathrm{ha}$, POLK $2 \mathrm{t} / \mathrm{ha}+600 \mathrm{~kg} \mathrm{NPK} / \mathrm{ha}$, POLK 5 t/ha dan $600 \mathrm{~kg} \mathrm{NPK/ha} \mathrm{(tanpa} \mathrm{POLK).}$ Intensitas serangan hama PBK di lokasi penelitian tergolong ringan. Pemberiaan POLK dengan menggunakan bioaktivator MOL pepaya dapat menekan penggunaan pupuk anorganik.

Limbah kulit kakao bisa dimanfaatkan sebagai pupuk organik berupa kompos. Sementara kompos dapat dijadikan bahan media tanam yang sangat baik bagi pertumbuhan bibit tanaman kakao, karena pertumbuhan bibit kakao di lapangan sangat ditentukan oleh pertumbuhan tanaman selama di pembibitan, yang pada gilirannya akan sangat menguntungkan juga bagi pertumbuhan tanaman kakao selanjutnya. Hasil penelitian $^{(20)}$ menunjukkan bahwa pemberian kompos dari kulit buah kakao dengan dosis $100 \mathrm{~g}$ per polybag memberikan pertumbuhan bibit tanaman kakao yang terbaik dibandingkan 
perlakuan lainnya yaitu $0,25,50$, dan 75 gram per polybag kompos kulit buah kakao.

Selain limbah kulit kakao dapat dimanfaatkan sebagai pupuk organik/kompos, juga dapat dimanfaatkan sebagai pakan ternak. Hasil penelitian menunjukkan bahwa pemanfaatan Kulit Buah Kakao (KBK) setelah diolah menghasilkan respon yang lebih baik, dibandingkan dengan KBK tanpa diolah. Pemanfaatan KBK diharapkan dapat dijadikan sebagai stok bahan pakan dan mengatasi kekurangan pakan hijauan terutama di musim kemarau dan dapat meningkatkan produktivitas atau pengembangan populasi ternak ruminansia di wilayah sentra perkebunan kakao ${ }^{(21)}$.

Pengembangan demfarm Takalala dapat dijadikan model perkebunan kakao secara terpadu antara tanaman kakao, limbah kakao dan pemanfaatan limbahnya dalam satu siklus produksi yang pada akhirnya menghasilkan zero waste yaitu nol limbah, tak ada bahan terbuang sebagai bentuk pertanian ramah lingkungan.

Ditinjau dari sistem sirkulasi atau arus pengunjung terlihat bahwa pengunjung tidak melewati zona produksi. Pertimbangannya agar tetap konsisten dengan prinsip dasar dalam penataan areal kawasan, yaitu: (1) Menciptakan suasana areal menjadi menarik dan asri, tanpa mengganggu aktifitas budidaya dan pengolahan, (2) Memberikan kenyamanan rekreasi bagi pengunjung, (3) Menjaga objek agrowisata dan kelestarian lingkungan.

Membangun dan mengembangkan agrowisata berwawasan lingkungan membutuhkan terbinanya sumberdaya alam dan lingkungan hidup yang lestari, sebaliknya dari hasil usaha pengembangan budidaya agro dan wisata yang dihasilkannya dapat untuk melestarikan sumberdaya alam dan lingkungan hidup. Agrowisata merupakan usaha agrobisnis yang membutuhkan keharmonisan dengan lingkungan hidup dalam segala aspek. Lestarinya sumberdaya lahan pertanian akan mempunyai dampak positif terhadap pelestarian lingkungan hidup yang berkelanjutan ${ }^{(22)}$.

\section{KESIMPULAN}

Keberadaan demfarm Takalala cukup strategis dan memenuhi syarat sebagai demfarm kakao karena terletak pada lokasi dan basis pengguna. Sarana dan prasarana serta infrastruktur menuju lokasi demfarm tersedia cukup memadai dan dapat dikunjungi dengan transportasi darat secara mudah dan nyaman. Bila dikaitkan dengan potensi pertanian/perkebunan di Kecamatan Marioriwawo adalah padi sawah dan kakao, maka keberadaan demfarm Takalala sangat diperlukan sesuai dengan misi dan visi demfarm. Bila dikaitkan dengan potensi wisata di
Kabupaten Soppeng dan di kabupaten di sekitarnya, maka potensi demfarm Takalala cukup berpeluang untuk dimodifikasi, direncanakan dan dikemas menjadi kawasan agrowisata berbasis kakao dan berbasis masyarakat/petani serta berwawasan lingkungan.

Konsep penataan lanskap demfarm dan agrowisata kakao berwawasan lingkungan dapat dijadikan model kawasan untuk diseminasi inovasi teknologi praproduksi (pembibitan), produksi, dan pascaproduksi (pengolahan dan pemasaran) kakao bagi para petani/kelompok tani, tempat penelitian/penerapan teknologi bagi para peneliti/imuwan/akademisi, pengembangan ilmu pariwisata bagi masyarakat sekitar, menambah wawasan iptek tentang kakao sekaligus sebagai tempat rekreasi bagi pengunjung/wisatawan, yang memiliki nilai-nilai pelestarian lingkungan dan yang semuanya dikemas dalam satu konsep zero waste (nol limbah) dan berkelanjutan di Kabupaten Soppeng.

Konsep dasar desain yaitu agrowisata kakao berbasis masyarakat. Desain lanskap diwujudkan dalam bentuk site plan yang didominasi pola geometris yang terbentuk dari elemen lunak tapak seperti tanaman kakao dan tanaman hias taman tematiknya. Zonasi yang dibuat, yaitu : Zona umum (4\%), Zona rekreasi (9\%), Zona produksi $(81 \%)$, dan Zona pribadi $(6 \%)$. Kendala tapak terletak pada faktor-faktor fisik yang masih mungkin bisa diminimalisasi.

\section{PERSANTUNAN}

Terima kasih kami sampaikan kepada Pusat Teknologi Produksi Pertanian (PTPP), Kedeputian Teknologi Agroindustri dan Bioteknologi (TAB) Badan Pengkajian dan Penerapan Teknologi (BPPT) yang telah membiayai penelitian ini. Kami juga mengucapkan terima kasih kepada Kepala Program Pengembangan Teknologi Produksi Kakao Dalam Rangka MP3EI Koridor IV (Sulawesi Selatan), Group Leader (GL) WBS 1 dan Leader (L) WP 3 atas fasilitasi, bantuan dan kerja samanya. Kami ucapkan terima kasih atas bantuan selama penelitian kepada Dinas Perkebunan Kabupaten Soppeng, Kecamatan Marioriwawo dan Lurah Tettikenrarae beserta warganya, Ketua Gapoktan dan anggotanya, Bapak Hasnul pemilik lahan demfarm, serta dinas terkait di Kabupaten Soppeng Sulawesi Selatan.

\section{DAFTAR PUSTAKA}

1. Anonim, (2008). Program Gerakan NasionalPercepatan Revitalisasi Kakao Nasional(GERNAS) Masukan strat egis dari ForumKemitraan Kakao Berkelanj utan 
(Cocoa Sustainability partnership). Disunting ol eh Jeff Neilson (atas permi ntaan dariACIAR). Kemitraan Australia Indonesia.

2. Anonim, (2015). Statistik Perkebunan Indonesia 2014-2016. Kakao. Dirjen Perkebunan Jakarta, Desember 2015.

3. Poerbo, Hasan, (1999). Lingkungan Binaan Untuk Rakyat, Penerbit Yayasan Akatiga, Bandung.

4. John Ikerd, 1990. Sustainability's Promise. Jurnal Soil and Water Conservation (JanFeb 1990), 45(1) : p.4.

5. Gold, S.M. (1980). Recreation Planning and Design. McGraw-Hill Book Co. NewYork.197 p.

6. Anonim, (2015). Statistik Daerah Kecamatan Marioriwawo 2015. BPS Kabupaten Soppeng.

7. Amali, Noor, (2014). Demonstrasi Teknologi : Metode Penyuluhan yang bersentuhan langsung dengan petani. 04 Desember 2014. Balai Pengkajian Teknologi Pertanian (BPTP) Kalimantan Selatan. Jl. Panglima Batur Barat No.4, Banjarbaru, Kalimantan Selatan 70711, Indonesia.

8. Anonim, (2015). Penerapan Metode Penyuluhan. Kementerian Pertanian, Badan pengembangan Sumber Daya Manusia Pertanian-SekolahTinggi Penyuluhan Pertanian.

9. Nurisjah S. (2001). Pengembangan kawasan wisata agro (Agrotourism). Buletin Tanaman dan Lanskap indonesia. 4(2): 2023.

10. Subowo. (2002). Agrowisata meningkatkan Pendapatan Petani. Warta Penelitian dan Pengembangan Pertanian Vol. 24 No.1 2002. http : //database.deptan. go.id/agrowisata.

11. Budiarti T, A.D.N. Makalew, N. Nasrullah, Saptana, U. Haryati. (2012). Potential Evaluation of Community-Based Agritourism in Banyuroto and Ketep Rural Landscape Magelang Distric Central Java Indonesia. Symposium IFLA Asia Pacific Shanghai (CN). Oct 23-25th.

12. Maharani R. dan T. Budiarti. (2010). Studi Potensi Lanskap Perdesaan untuk Pengembangan Agrowisata berbasis Masyarakat di Cigombong, Bogor. Dalam Prosiding Simposium Nasional IALI. Bogor (ID). November.
13. Muzha V.K, H. Ribawanto, M. Hadi, (2013). Pengembangan agrowisata dengan pendekatan Community Based Tourism (Studi pada Dinas Pariwisata Kota Batu dan Kusuma Agrowisata Batu). Jurnal Administrasi Publik. Jurnal Elektronik Mahasiswa Jurusan Administrasi Publik. 1(3). http//administrasipublik.studentjournal. ub.ac.id/ index.php/jap/article/view/81/75.

14. Global Ecovillage Network (GEN). (2005). Community Sustainabiliy Assessment. Http://gen.ecovillage.org/activities/ csa/pdf/CSAEnglish. pdf.

15. Eckbo Garrett, (1995). The Art of Home Landscaping. Mc. Graw Hill Book Company, New York.

16. Bell S. (2008). Design for Outdoor Recreations. New York (US): Taylor \& Francis.

17. Ling, A.H., (1984). Cocoa Nutrition and Manuring on Inland Soil in Peninsular Malaysia. The Planter 60 (694) : 12-2418.

18. Shepherd, R and Y.T. Ngau, 1984. Utilization of by Product of Cocoa Bean Processing. Int.Conf. On Cocoa and Coconut, Malaysia. 17 p.

19. Nappu Basir, dkk. (2012). Efektivitas penggunaan beberapa mikro organisme local (MOL) dalam pengolahan limbah kakao menjadi pupuk organik dan aplikasinya pada tanaman kakao produktif. Litbang Kementerian Pertanian Sulawesi Selatan. www.sulsel. litbang.deptan. go.id

20. Sri Yoseva, Ardian dan Chris Mariana, (2013). Pemanfaatan Kompos Kulit Buah Kakao Pada Pertumbuhan Bibit Kakao Hibrida (Theobroma cacao L). J. Agrotek. Trop. 2 (1): 23-27

21. W. Puastuti dan IWR. Susana, (2014). Potensi dan Pemanfaatan Kulit Buah Kakao sebagaiPakan Alternatif Ternak Ruminansia. Wartazoa Vol. 24 No. 3 Tahun 2014 HIm. 151-159. DOI: http://dx.doi.org/10.14334/wartazoa.v24i3.10 72

22. B. Pamulardi, (2006). Pengembangan agrowisata berwawasan lingkungan (Studi kasus Desa Wisata Tingkir Salatiga). Tesis. Program Studi Ilmu Lingkungan. Program Pasca Sarjana Universitas Diponogoro, Semarang 